\title{
CMOS Humidity Sensor System Using Carbon Nitride Film as Sensing Materials
}

\author{
Sung Pil Lee ${ }^{1, *}$, Ji Gong Lee ${ }^{2}$ and Shaestagir Chowdhury ${ }^{3}$ \\ ${ }^{1}$ Department of Electronic Engineering, Kyungnam University, Masan, Kyungnam 631-701, Korea \\ 2 Electrical Engineering and Computer Science, Case Western Reserve University, Cleveland, Ohio \\ 44106, USA \\ ${ }^{3}$ Intel Corporation, Hillsboro, OR 97124, USA
}

* Author to whom correspondence should be addressed; E-mail: sensors@ kyungnam.ac.kr; Tel: 82-55-249-2642, Fax: 82-55-249-2838,

Received: 12 February 2008 / Accepted: 10 April 2008 / Published: 14 April 2008

\begin{abstract}
An integrated humidity sensor system with nano-structured carbon nitride film as humidity sensing material is fabricated by a $0.8 \mu \mathrm{m}$ analog mixed CMOS process. The integrated sensor system consists of differential humidity sensitive field effect transistors (HUSFET), temperature sensor, and operational amplifier. The process contains two poly, two metal and twin well technology. To form $\mathrm{CN}_{\mathrm{x}}$ film on $\mathrm{Si}_{3} \mathrm{~N}_{4} / \mathrm{Si}$ substrate, plasma etching is performed to the gate area as well as trenches. $\mathrm{CN}_{\mathrm{x}}$ film is deposited by reactive RF magnetron sputtering method and patterned by the lift-off technique. The drain current is proportional to the dielectric constant, and the sensitivity is $2.8 \mu \mathrm{A} / \% \mathrm{RH}$.
\end{abstract}

Keywords: Integrated sensors, Humidity, CMOS, Carbon nitride film

\section{Introduction}

Semiconductor sensors, where semiconductor materials are mainly responsible for the sensor operation and/or semiconductor fabrication processes are applied to sensor fabrication, is an interesting topic to be investigated in terms of the developing miniaturized and high performance sensors. A semiconductor humidity sensor, a typical chemical sensor, is widely used in wide range of measurements and control applications, including those in home appliances, industries, agriculture, hospitals, and laboratories that need greater accuracy and extreme conditions. In order to satisfy a wide 
range of applications, expected parameters of humidity sensors are sensitivity, response time, reproducibility, long-term stability, selectivity, durability and low cost.

The importance of integrated sensors has been increasingly recognized with the development of technology and science, as miniaturization of sensors offers general advantages with respect to batch fabrication and reduction of cost [1]. However, integrated humidity sensors, using clean semiconductor fabrication process and inorganic materials as sensing materials, have not yet been matured as a commercial product in the global market. Fortunately, several researchers have recently reported some micro humidity sensors, such as a capacitive humidity sensor with on-chip thermal reset [2], a CMOS humidity sensor [3] and a capacitive humidity sensor manufactured by a CMOS-MEMS technique [4], and a company has introduced a new humidity and temperature sensor using CMOS micro-machined chip technology [5]. Humidity sensors have applied the polymer materials with a dip-coating or spin coating method as sensing layer. However, polymer materials can not stand temperature higher than $900 \mathrm{C}$ to make on-chip microsensors on semiconductor substrate, such as silicon. And the polymer layer of the humidity sensors exhibits varying degrees of sensitivity to the same external influences because of hysteresis and swelling. The aging of this layer can also lead to data errors in the humidity signals.

The first study of carbon nitride $\left(\mathrm{CN}_{\mathrm{x}}\right)$ was focused only on synthesizing the stoichiometric $\beta-\mathrm{C}_{3} \mathrm{~N}_{4}$ phase, which was suggested as a new super hard material that might have similar or superior hardness and bulk modulus of diamond [6]. However, the stoichiometric $\beta-\mathrm{C}_{3} \mathrm{~N}_{4}$ phase was synthesized in 1998 [7]. One of the most significant obstacles to synthesize the stoichiometric $\beta-C_{3} N_{4}$ is the hydrogen contamination that can break C-N bonds to N-H and C-H bonds on the films. Hydrogen is usually created by the water molecules that are diffused from the vacuum chamber wall or outside. However, if one could make use of hydrogen defects that were formed intentionally and bonded weakly, carbon nitride would be an attractive candidate material for integrated humidity sensors based on the silicon process [8], because of the high melting point and thermal stability of the carbon nitride films.

In this study, the integrated humidity sensor system with OP amp, using the CNx films as a sensing material, has been designed, simulated, and fabricated based on standard CMOS fabrication process.

\section{Design and Fabrication of Integrated Humidity Sensor System}

A CMOS humidity sensor system with two stages OP amp is designed by $0.8 \mu \mathrm{m}$ CMOS technology. It consists of a humidity sensor block, a temperature sensor block and an operational amplifier block for signal amplification and processing in one chip. The two stage operational amplifier has a differential input stage, second gain stage, and output buffer shown in Figure 1. Frequency compensation is necessary for close-loop stability due to a negative-feedback connection. The simplest frequency compensation technique employs the Miller effect by connecting a compensation capacitor $\mathrm{C}_{\mathrm{o}}$ across the high-gain stage. Due to unintentional feed-forward path through the Miller capacitor, a right-half-plane zero is also created and the phase margin is degraded. Such a zero, however, can be removed if a proper nullifying resistor in inserted in series with the Miller capacitor $[9,10]$.

The NMOSFET $M_{1}$ and $M_{2}$ provide the input differential pair, and the PMOSFET $M_{3}$ and $M_{4}$ provide the active load, respectively in Figure 1. The differential input stage is biased by the current 
mirror $\mathrm{M}_{5}$ and $\mathrm{M}_{8}$, in which the reference current is determined by the internal resistor connected with an adjustable external resistor (circle A). The second stage which means the output stage consists of the common source-connected NMOSFET $\mathrm{M}_{7}$. Transistor $\mathrm{M}_{8}$ provides the bias current for $\mathrm{M}_{7}$ and acts as the active load. An internal compensation capacitor (circle B) and transistor $\mathrm{M}_{9}$ are included for stability. A bias circuit is determined with a stable transconductance which is matched to the conductance of a bias resistor. Therefore, the transistor transconductances are not dependent on the power-supply voltage, as well as the process parameters and the temperature variations. To prevent the zero-current state in the bias circuit, a start-up circuit is included.

Figure 1. Schematic view of two-stage CMOS operational amplifier with robust bias.

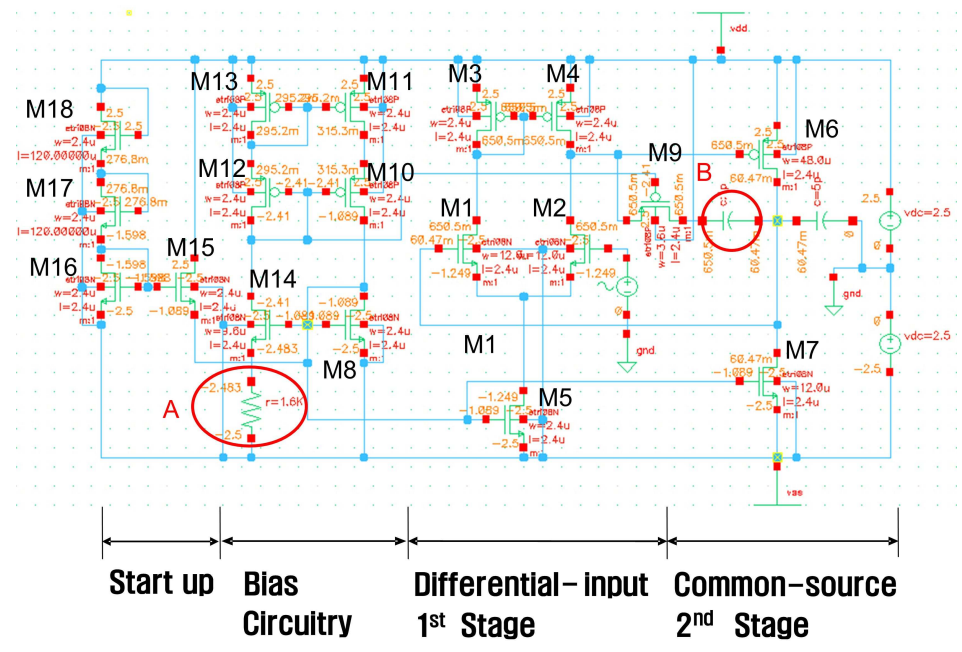

The layout of the operational amplifier is shown in Figure 2. Each function block in the operational amplifier are separated by well and metal guard rings. Input lines are given to twisted pair by two metal layers because it is a particularly effective and simple way of reducing both magnetic and capacitive interference pickup. Twisting the wires tends to ensure a homogeneous distribution of capacitances. Feedback capacitance of $5 \mathrm{pF}$ is designed near to amp block. The common centroid placement design and dummy poly rings are employed for reducing the mismatch from over etching and electrical noses. Input FETs of the differential operational amplifier are placed also taking into consideration operational matching between halves of the cell layout.

Figure 2. Layout (a) and photograph (b) of a differential operational amplifier block.

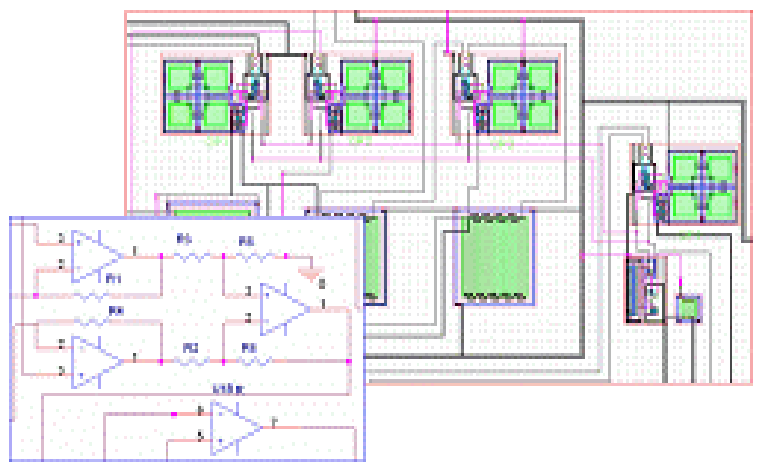

(a)

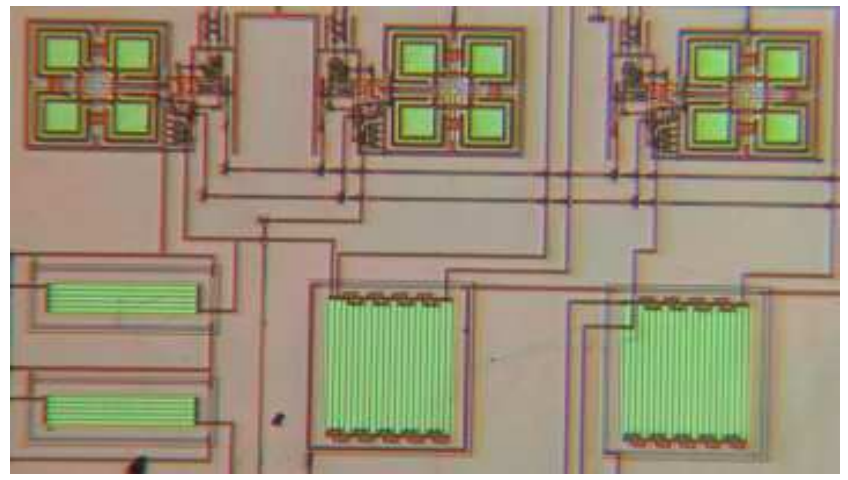

(b) 
Figure 3 shows the design of a four humidity sensitive field effect transistors (HUSFETs): $\mathrm{SPa}, \mathrm{SPb}$, $\mathrm{SNa}$, and $\mathrm{SNb}$. The middle letter, ' $\mathrm{P}$ ' or ' $\mathrm{N}$ ' means the channel type of the FET sensor and the last letter ' $a$ ' or ' $b$ ' is the type of the sensor structure. The type ' $a$ ' is a multi-finger gate MISFET structure with $60 \times 3 / 8 \mathrm{~W} / \mathrm{L}$ ratio, and 'b' is an interdigitated source-drain MISFETs with $(60 \times 5 / 8) \mathrm{W} / \mathrm{L}$ ratio, which are covered with gate electrode. Through the parallel connection of SNa and SPa, these two HUSFETs operate as a single HUSFET with a width equal to the sum of the individual transistor width, having a same length. The drain and source areas can be shared with adjacent HUSFETs. Two benefits are achieved with this layout: (1) smaller layout size and (2) the reduction of the depletion capacitances in source and drain. The reduction of depletion capacitance plays an important role of the protection of latch-up in analog design or in output driver design. No latch-up was found in this sensor system. Figure 4 is a metallurgical microscope image of the sensor block in a fabricated chip.

Figure 3. Layout of HUSFETs.

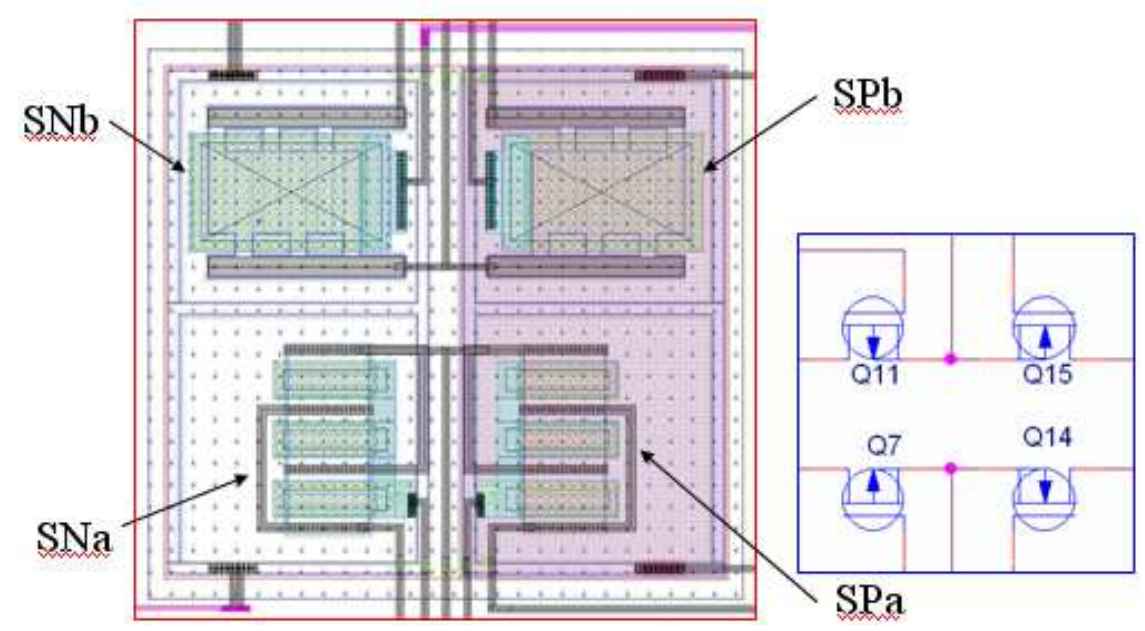

Figure 4. Image of sensor block.

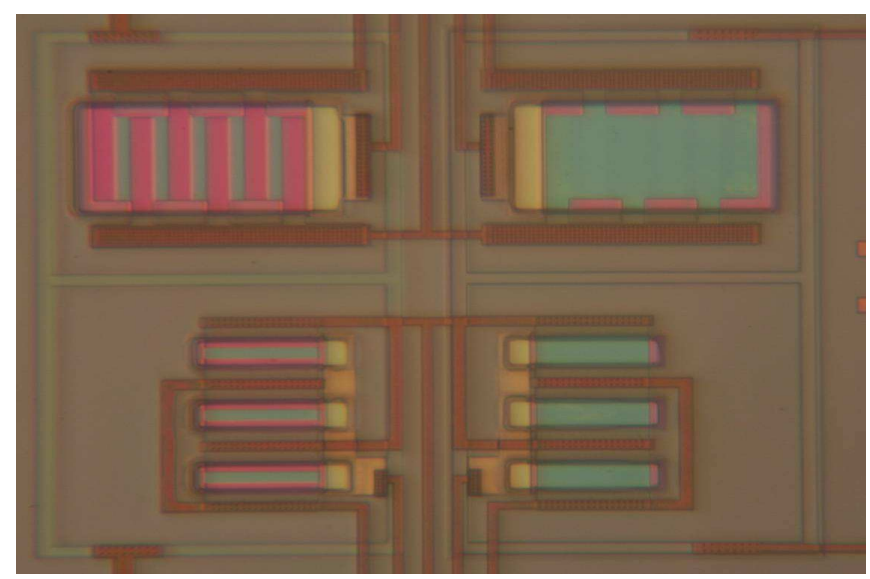

A differential HUSFET has a pair of transistors, a sensing transistor (denoted ' $S$ ') and a reference transistor (denoted R), as shown in Figure 5. A reference transistor is applied to eliminate the effect of unwanted factors, temperature, other gases, electrical noises, etc. The differential signal from sensor and reference is transmitted to the amplifier block. The fabrication is based on $0.8 \mu \mathrm{m} \mathrm{CMOS}$ 
technology which contains two poly, two metal and twin well process. Some steps for sensing area of HUSFET are added in the conventional CMOS process. For the formation of $\mathrm{CN}_{\mathrm{x}}$ film on the gate layer, the plasma etching is performed to each gate along with trench. $\mathrm{CN}_{\mathrm{x}}$ film is deposited by a reactive $\mathrm{RF}$ magnetron sputtering system with DC bias and patterned by the lift-off technique. To fulfill the requirement of differential sensor, water permeable gold layer is deposited only on the gate region of the sensing transistor. After that, the photo resist is coated on the gold pattern with a mask. The photo resist for passivation is patterned on the gate area of reference FETs to protect the reaction with water vapor.

Figure 5. Structure of n-channel differential HUSFET.

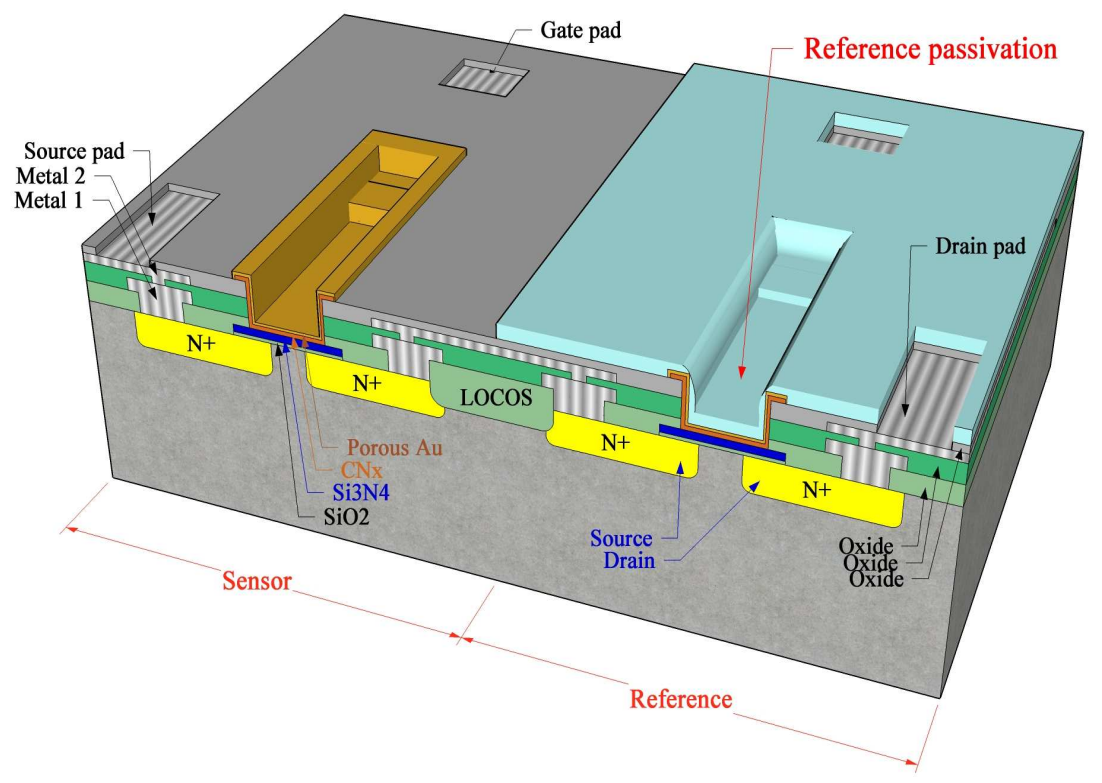

\section{Results and Discussion}

$\mathrm{AC}$ response of open loop gain in the operational amplifier is expressed as:

$$
\mathrm{A}_{\mathrm{OL}}(\mathrm{f})=\frac{A_{O}}{1+j \frac{f}{f_{P D}}}
$$

where, $A_{o}$ is a low-frequency open-loop gain and $f_{P D}$ is a dominant-pole frequency. The unity-gain bandwidth is written as

$$
\mathrm{f}_{\mathrm{T}}=\mathrm{f}_{\mathrm{PD}} \mathrm{A}_{\mathrm{O}}
$$

and is also called the gain-bandwidth product. The open loop gain $\mathrm{A}_{\mathrm{o}}$ is about $85 \mathrm{~dB}$ and the dominantpole frequency $\mathrm{f}_{\mathrm{PD}}$ is about $140 \mathrm{~Hz}$ shown in Figure 6 . The unity-gain bandwidth $\mathrm{f}_{\mathrm{T}}$ (about $10 \mathrm{MHz}$ ) can be obtained at around $1 \mathrm{~dB}$ in Figure 6. Its value is a little bit higher than the calculated one from equation (2). 
Figure 6. Bode plot for open loop AC response.

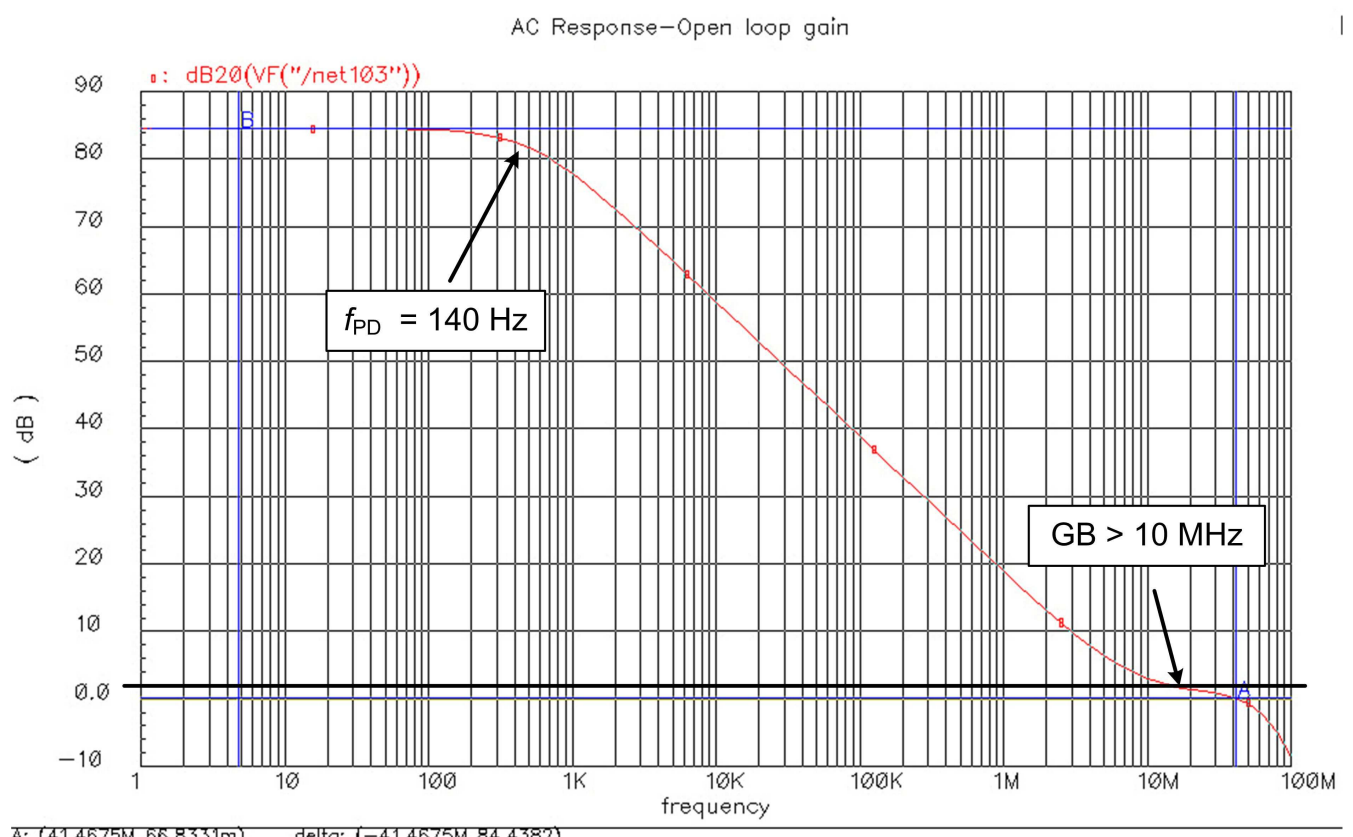

$\begin{array}{ll}\text { A: }(41.4675 \mathrm{M} 66.8331 \mathrm{~m}) & \text { delta: }(-41.4675 \mathrm{M} \\ \mathrm{B}:(4.7799884 .565) & \text { slope: }-2.63625\end{array}$

Phase margin and gain margin that are easily evaluated from the Bode diagram are used for a main criterion of frequency response stability. The phase margin PM is the amount of additional phase lag at the gain crossover frequency required to bring the system to the verge of stability, and the gain margin $(\mathrm{GM})$ is the reciprocal of the magnitude $|G(j w)|$ at the frequency at which the phase angle is $-180^{\circ}$. The GM is positive if it is more than unity and negative if less than unity. The positive GM (in decibels) means that the system is stable and the negative GM means the opposite. For satisfactory performance of the sensor system, the PM should be between $30^{\circ}$ and $60^{\circ}$, and the GM should be greater than $6 \mathrm{~dB}$. In Figure 7, the $\mathrm{GM}$ is about $27 \mathrm{~dB}$ and the $\mathrm{PM}$ is about $55^{\circ}$, respectively.

Figure 7. AC response of unity gain operational amplifier.

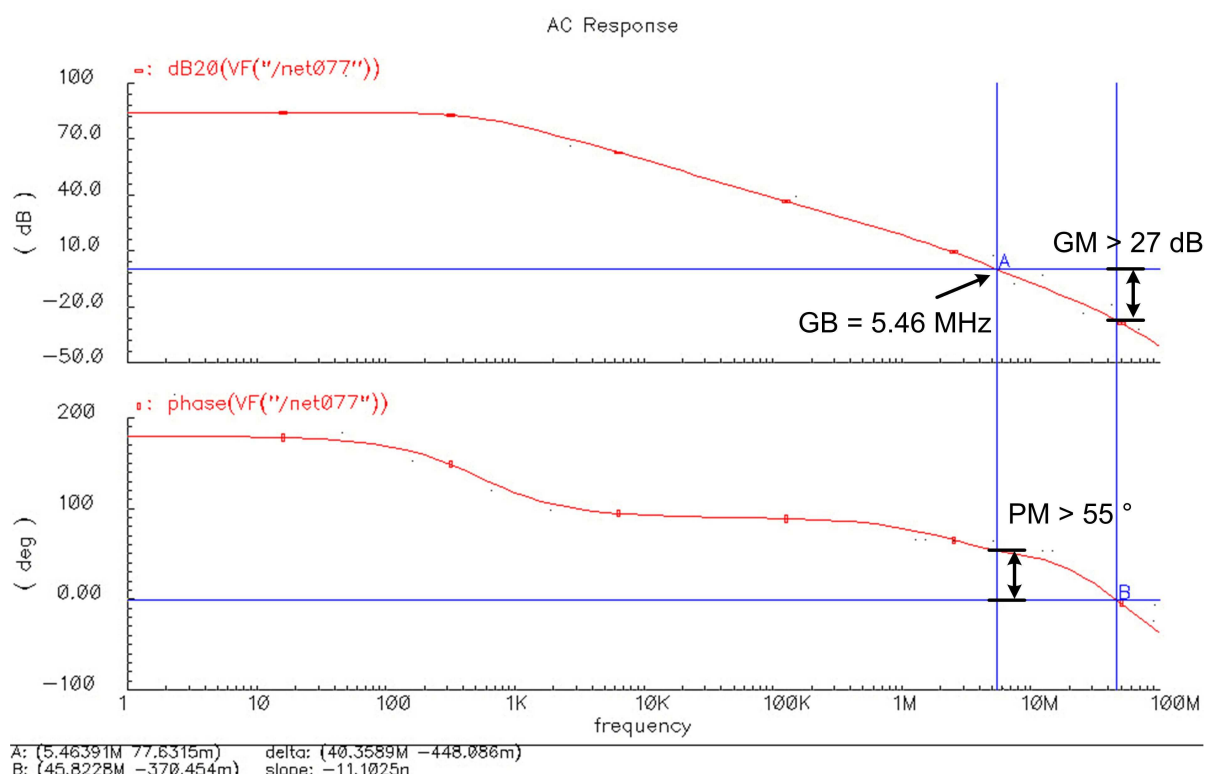

A: $(5.46391 \mathrm{M}$
B: $(45.87 .6315 \mathrm{~m})$ 
The maximum rate of change of the output voltage is the slew rate $S R$ of the operational amplifier, the unit of which is usually given as volts per microsecond and written as

$$
\mathrm{SR}=\left(\frac{d V_{o}}{d t}\right)_{\max }=\frac{I_{q}}{C_{c}}
$$

where, $\mathrm{V}_{\mathrm{o}}$ is a output voltage, $\mathrm{C}_{\mathrm{c}}$ is a compensation capacitor, and $\mathrm{I}_{\mathrm{q}}$ is a bias current. Although the rate of change in output voltage can be either positive or negative, the $S R$ is defined as a positive quantity. The settling time is the time that output is settled to within $\pm 0.1 \%$ of its final value, when the operational amplifier is connected as a unit-gain follower and step voltage $1 \mathrm{~V}$ is applied at the input. From Figure 8, it shows that the $S R$ is $10 \mathrm{~V} / \mathrm{uS}$ and the settling time is $130 \mathrm{nS}$ under $5 \mathrm{pF}$ load capacitor.

Figure 8. Slew rate and settling time of unity gain operational amplifier.

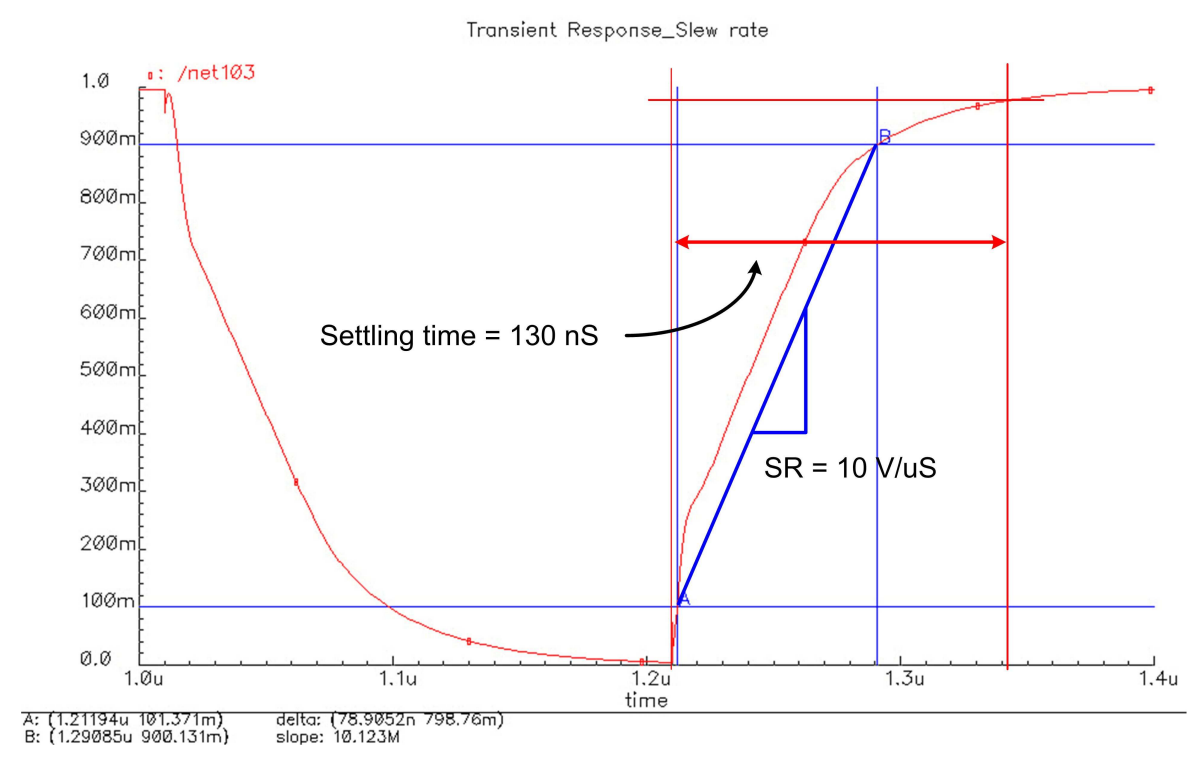

The electrical characteristics of the fabricated CMOS transistors and HUSFETs are measured by a semiconductor test and analyzer (CATS CA-EDA) and C-V plotter (HP 4280A) in self-designed measurement chamber. To avoid condensation of water vapor on chamber wall or pipelines, caused by the different temperature between input vapor and chamber inside, the devices and reference sensors put together in the constant-temperature chamber controlled by PID. Figure 9 shows the currentvoltage characteristics of nMOSFET with substrate bias. The poly-nitride etch stop process is applied to nMOSFET and HUSFET both. However, HUSFET has the humidity sensing layer $\left(\mathrm{CN}_{\mathrm{x}}\right.$ film $)$ in gate and NMOSFET has not. NMOSFET with 180/80 aspect ratio presents a typical MOSFET curves as much as the conventional MOSFET, as shown in Figure 9. As would be expected, the added polynitride etch stop process for the sensing area on the gate does not noticeably affect the original CMOS process. 
Figure 9. Current-voltage curves of fabricated nMOSFET $(\mathrm{W} / \mathrm{L}=180 / 8)$.

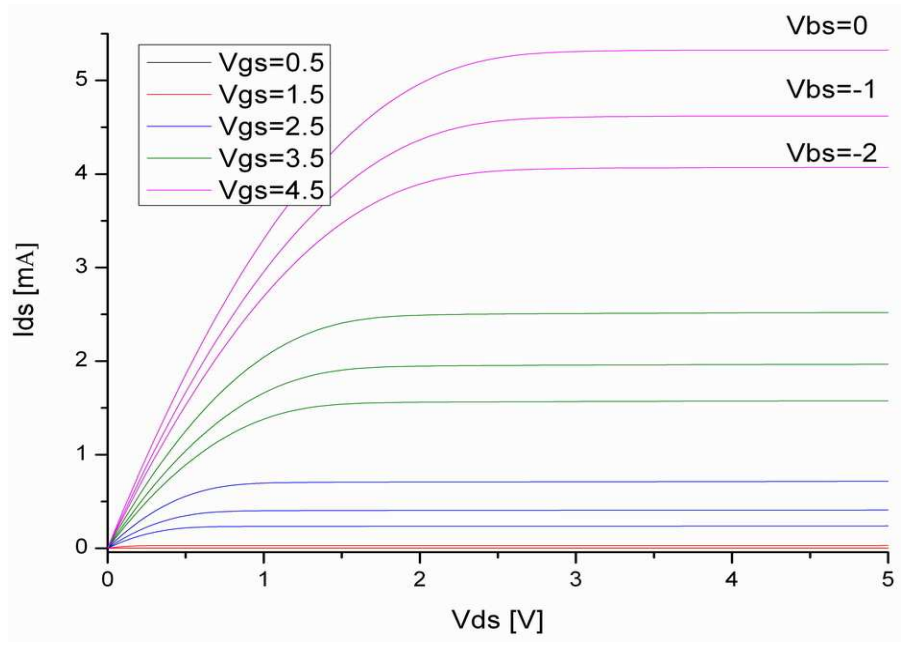

The threshold voltage of HUSFET is given as [11]

$$
\mathrm{V}_{\mathrm{T}}=-\phi_{M S}+\left(-Q_{s s}-Q_{i}-Q_{d}\right) / C_{i}^{\prime}+2 \phi_{F}
$$

where $\psi$ ' ${ }_{\text {MS }}$ is the work function difference between the gate metal and substrate material, $\mathrm{Q}_{\mathrm{ss}}$ is the charge density of the fixed surface state, $Q_{i}$ is the effective interface charge density, $Q_{d}$ is the charge density per unit area in depletion region and $\psi_{\mathrm{F}}$ is the Fermi potential of the substrate. The porous $\mathrm{Au}$ electrode is deposited on the structure of $\mathrm{C}_{3} \mathrm{~N}_{4} / \mathrm{Si}_{3} \mathrm{~N}_{4} / \mathrm{SiO}_{2} / \mathrm{Si}$ in HUSFET gate layer, as shown in Fig. 10. The capacitance per unit area at inversion state, $\mathrm{C}_{\mathrm{i}}$, , can be expressed as [12]

$$
\frac{1}{\mathrm{C}_{\mathrm{i}}^{\prime}}=\frac{1}{C_{S i}}+\frac{1}{C_{i n}}
$$

and

$$
C_{i n}=C_{o x} C_{s n} /\left\{\left(C_{o x}+C_{s n}\right)+\left(C_{o x} C_{s n} d_{c n}\right) / \varepsilon_{o x} \varepsilon_{c n}\right\}
$$

where $\mathrm{C}_{\mathrm{si}}, \mathrm{C}_{\mathrm{ox}}, \mathrm{C}_{\mathrm{sn}}$ and $\mathrm{C}_{\mathrm{cn}}$ are the capacitance of unit area in depletion region of substrate, $\mathrm{SiO}_{2}, \mathrm{Si}_{3} \mathrm{~N}_{4}$ and $\mathrm{C}_{3} \mathrm{~N}_{4}$, respectively, and $\mathrm{d}_{\mathrm{cn}}$ is the thickness of carbon nitride film, $\varepsilon_{o}$ is the relative permittivity of free space and $\varepsilon_{\mathrm{cn}}$ is the relative permittivity of $\mathrm{CN}_{\mathrm{x}}$ film. When hygroscopic $\mathrm{CN}_{\mathrm{x}}$ film is exposed to water molecular, the modified dielectric constant can be written by Looyenga's empirical equation [13]

$$
\varepsilon_{s}=\left\{\gamma\left(\varepsilon_{w}^{1 / 3}-\varepsilon_{c n}^{1 / 3}\right)+\varepsilon_{c n}^{1 / 3}\right\}^{3}
$$

where $\gamma$ is the fractional volume of water in the carbon nitride film and $\varepsilon{ }_{w}$ is the dielectric constant of water given by [14]

$$
\varepsilon_{w}=78.54\left\{1-4.6 \times 10^{-4}(T-298)+8.8 \times 10^{-6}(T-298)^{2}\right\}
$$

where $\mathrm{T}$ is temperature in Kevin. Shibata et al. have reported the calculated $\gamma$ in a polyimide film [15]. 
Figure 10. Inversion state of nHUSFET; (a) cross sectional view and (b) energy band diagram.

\section{Inversion $\left(\mathbf{V}_{\mathrm{TH}}<\mathrm{V}_{\mathrm{GB}}\right)$}
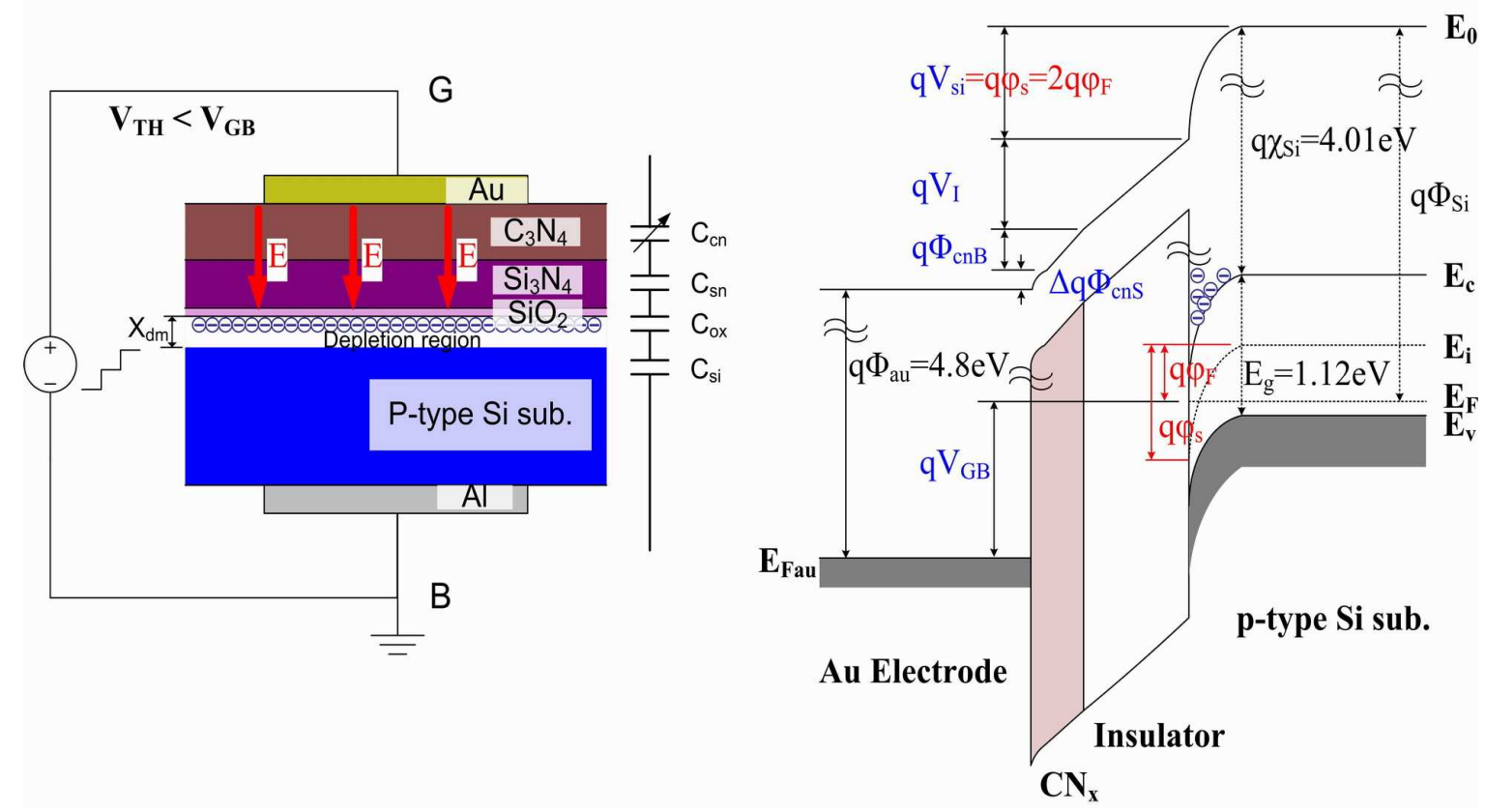

The humidity sensing properties of an n-channel HUSFET ( $\mathrm{SNa}$ ) is shown in Figure 11. When the ambient temperature is $25{ }^{\circ} \mathrm{C}$ and the relative humidity is $20 \%$, the threshold voltage of the n-channel $\operatorname{HUSFET}(\mathrm{SNa})$ is about $-11.1 \mathrm{~V}$ at $\mathrm{V}_{\mathrm{sb}}=0 \mathrm{~V}$.

Figure 11. I-V curve of an n-channel HUSFET.

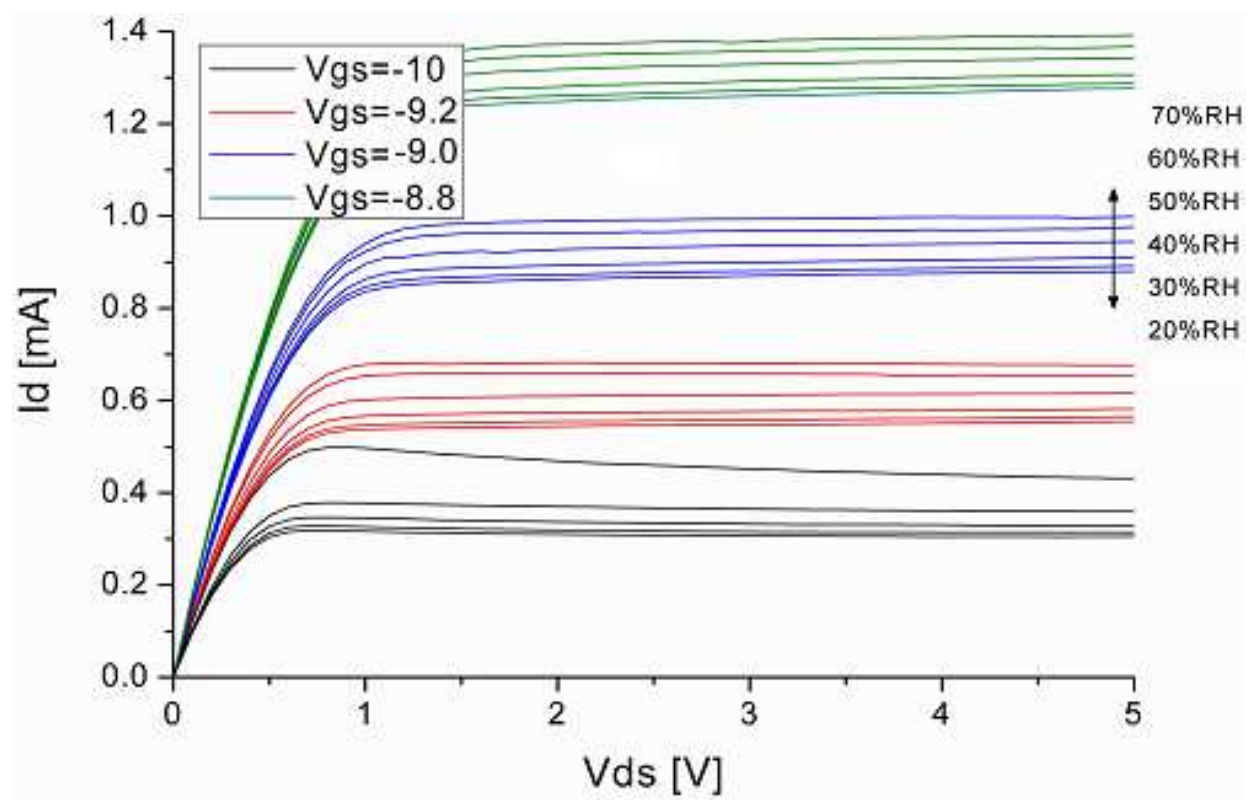

This value is in good agreement with the calculated value that was achieved from equation (4). The threshold voltage of nHUSFET is much lower than that of nMOSFET, because the $\mathrm{C}_{\mathrm{i}}$ is reduced and the interface charge density $\mathrm{Q}_{\mathrm{i}}$ is increased due to the deposition of carbon nitride. When the relative humidity increases from $20 \% \mathrm{RH}$ to $70 \% \mathrm{RH}$, the drain current of the $\mathrm{SNa}$ increases from 0.85 to 0.99 
$\mathrm{mA}$ at $\mathrm{V}_{\mathrm{gs}}=-9.0 \mathrm{~V}$ and $\mathrm{T}=25^{\circ} \mathrm{C}$. When water molecules meet carbon nitride layer through the porous gold layer of HUSFET gate, they are chemisorbed on the available sites of the carbon nitride surface by dissociative mechanism to form two hydroxyl ions for each water molecule, which possess a high local charge density and a strong electrostatic field, and the proton reacts with an adjacent surface $\mathrm{O}^{2-}$ group to form a second $\mathrm{OH}^{-}$group. Therefore, singly bonded water molecules are able to form dipole and to reorient freely under an externally applied gate field, resulting in an increase in the dielectric constant. This is also attributed to the threshold voltage and the drain current changes of HUSFET.

Figure 12 shows the relationship between the drain current and the relative humidity of nHUSFET. The gate voltage and the source-drain voltage are fixed at $\mathrm{V}_{\mathrm{gs}}=-9.0 \mathrm{~V}$ and $\mathrm{V}_{\mathrm{ds}}=4 \mathrm{~V}$. If a sensitivity is defined as $S=d I_{D} / d R H$, then the sensitivity of the $\mathrm{SNa}$ is $2.8 \mu \mathrm{A} / \% \mathrm{RH}$.

Figure 12. Drain current change as a function of relative humidity.

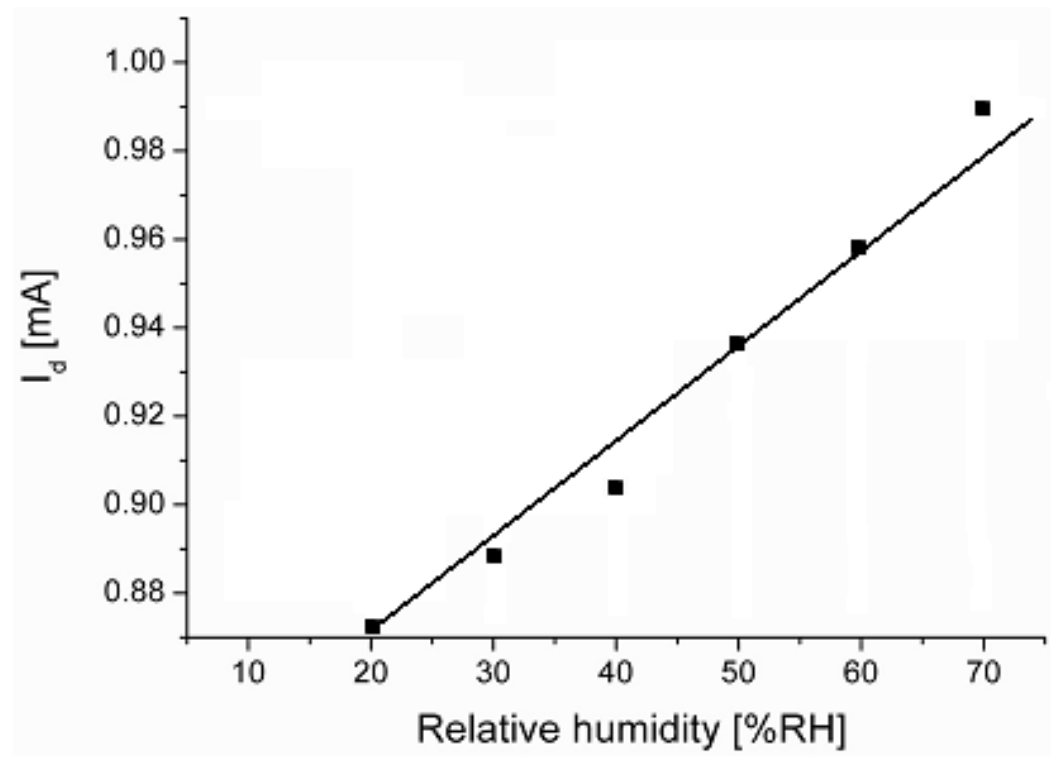

\section{Conclusions}

The integrated micro humidity sensor system, using $\mathrm{CN}_{\mathrm{x}}$ films as the sensing material, has been designed and fabricated with an operational amplifier based readout circuit. The poly-nitride etch stop process has been tried to form the sensing area in a standard CMOS process. The operational amplifier revealed the stable operation for the signal processing of sensor part, so that unity gain bandwidth was more than $5.46 \mathrm{MHz}$ and slew rate was more than $10 \mathrm{~V} / \mathrm{uS}$, respectively. The drain current of the $\mathrm{n}$ channel HUSFET increased from 0.85 to $0.99 \mathrm{~mA}$ as the relative humidity increased from 20 to 70 $\% \mathrm{RH}$. The integrated micro humidity sensor system showed the sensitivity of $2.8 \mu \mathrm{A} / \% \mathrm{RH}$ at constant drain and gate bias.

\section{Acknowledgements}

This research was financially supported by the Ministry of Commerce Industry and Energy (MOCIE), and Korean Industrial Technology Foundation (KOTEF) through the Human Resource Training Project for Regional Innovation. 


\section{References and Notes}

1. Rittersma, Z. Recent achievement in miniaturized humidity sensors - a review of transduction techniques. Sensors and Actuators A 2002, 96, 196-210.

2 Kang, U.; Wise, K. D. A high -speed capacitive humidity sensor with on-chip thermal reset. IEEE Trans Electron Devices 2000, ED-47, 702-710.

3. Qiu, Y.Y.; Azeredo-Leme, C.; Alcacer, L.R.; Franca, J.E.A CMOS humidity sensor with on-chip calibration. Sensors and Actuators A 2001, 92, 80-87.

4. Dai, C.L.A capacitive humidity sensor integrated with micro heater and ring oscillator circuit fabricated by CMOS-MEMS technique. Sensors and Actuators B 2007, 122, 375-380.

5. www.sensorland.com/Homepage047.html.

6. Liu, A.Y.; Cohen, M. L. Prediction of new low compressibility solid. Science 1989, 245, 841-842.

7. Chowdhury, A.K.M.S.; Cameron, D.C.; Hashmi, M.S.J. Vibrational properties of carbon nitride films by Raman spectroscopy. Thin Solid Film 1998, 332, 62-68.

8. Lee, J.G.; Lee, S.P. Humidity sensing properties of CNx film by RF magnetron sputtering system. Sensors and Actuators B 2005, 108, 450-454.

9. Palmisano, G.; Paumbo, G. A compensation strategy for two-stage CMOS opamps based on current buffer. IEEE Trans. Circuit Syst. I Fundam. Theory Apply 1997, 44, 257-262.

10. Allen, P. E.; Holberg, E. D. R. CMOS analog circuit design $2^{\text {nd }}$ ed., Oxford: Oxford, 2002; pp. 140-148.

11. Richman, P. MOS Field-Effect Transistors and Integrated Circuit, Wiley, New York, 1973, p 31.

12. Lee, S.P.; Park, K.J. Humidity sensitive field effect transistors. Sensors and Actuators B 1996, 35$36,80-84$.

13. Schubert, D.L.; Nevin, J.H. A polyimide-based capacitive humidity sensor. IEEE Trans Electron Devices 1985, ED-32, 1220-1223.

14. Hasted J. B. Aqueous Dielectrics, Chapman and Hall: London, 1973; pp. 37-38.

15. Shibata, H.; Ito, M.; Asakursa, A.; Watanabe, K. A digital hygrometer using a polyimide film relative humidity sensor. IEEE Trans Instrum. Meas. 1986, 45, 564-569.

(C) 2008 by MDPI (http://www.mdpi.org). Reproduction is permitted for noncommercial purposes. 